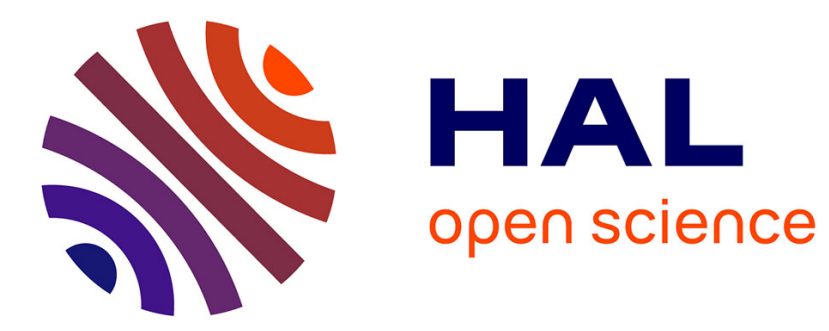

\title{
In-depth characterisation of a mixture composed of powder/pellets MX80 bentonite
}

Agustín Molinero Guerra, Nadia Mokni, Pierre Delage, Yu-Jun Cui, Anh

Minh A.M. Tang, Patrick Aimedieu, Frédéric Bernier, Michel Bornert

\section{To cite this version:}

Agustín Molinero Guerra, Nadia Mokni, Pierre Delage, Yu-Jun Cui, Anh Minh A.M. Tang, et al.. In-depth characterisation of a mixture composed of powder/pellets MX80 bentonite. Applied Clay Science, 2017, 135, pp.538-546. 10.1016/j.clay.2016.10.030 . hal-01515960v2

\section{HAL Id: hal-01515960 \\ https://hal-enpc.archives-ouvertes.fr/hal-01515960v2}

Submitted on 29 Jan 2021

HAL is a multi-disciplinary open access archive for the deposit and dissemination of scientific research documents, whether they are published or not. The documents may come from teaching and research institutions in France or abroad, or from public or private research centers.
L'archive ouverte pluridisciplinaire HAL, est destinée au dépôt et à la diffusion de documents scientifiques de niveau recherche, publiés ou non, émanant des établissements d'enseignement et de recherche français ou étrangers, des laboratoires publics ou privés.

\section{(1) (1) $\$$}

Distributed under a Creative Commons Attribution - NonCommercial - NoDerivatives 44.0 


\title{
In-depth characterisation of a mixture composed of powder/pellets MX80 bentonite
}

\author{
Agustín Molinero Guerra ${ }^{1,2}$, Nadia Mokni ${ }^{2}$, Pierre Delage ${ }^{1}$, Yu-Jun Cui ${ }^{1}$, Anh Minh Tang ${ }^{1}$, \\ Patrick Aimedieu $^{1}$, Frédéric Bernier ${ }^{3}$, Michel Bornert ${ }^{1}$ \\ ${ }^{1}$ Ecole des Ponts ParisTech, Laboratoire Navier, Marne la Vallée, France \\ ${ }^{2}$ Institut de Radioprotection et de Sûreté Nucléaire (IRSN), Fontenay-aux-Roses, France \\ ${ }^{3}$ Agence Fédérale de Contrôle Nucléaire (AFCN), Belgique
}

Abstract: Mixtures made up of bentonite powder and pellets are a possible candidate for making sealing plugs used in deep radioactive waste disposal due to their low permeability, high swelling capacity, favourable properties with respect to radionuclide retention and operational advantages in terms of placement in situ, that is much easier than that of precompacted bricks of bentonite/sand mixture. It is therefore essential to better understand their hydro-mechanical behaviour to optimize the design of the repository. In this context, the French Institute for Radiation Protection and Nuclear Safety (IRSN) has launched the SEALEX project (SEALing performance EXperiments) in which this work has been conducted.

Once the initially heterogeneous unsaturated powder/pellet (80/20) MX80 bentonite mixture is put in place, these sealing materials will be subject to coupled hydro-mechanical loadings: hydration due to the infiltration of pore water from the natural barrier and mechanical confinement resulting from the engineered barriers. The present work focuses on the different scales of the material: at the macroscopic scale, it is characterized by a heterogeneous distribution of pellets and powder of bentonite; at the microscopic scale, it is studied by several techniques (MIP, $\mu$-CT observations and SEM). From MIP results, a typical bimodal distribution was found for both pellet and powder. From $\mu$-CT and SEM observations, a heterogeneity was revealed in the internal structure of the pellet: heterogeneous density distribution of the clay minerals and presence of several high density elements.

Keywords: heterogeneous pellet/powder bentonite mixture; sealing plug; radioactive waste disposal; microstructure; mercury intrusion porosimetry; X-ray computed microtomography; scanning electron microscopy. 


\section{Introduction}

In the French concept of deep geological disposal for High Level and Intermediate Level Long Lived radioactive Wastes (HLW \& ILLLW), the wastes are emplaced within large diameter boreholes (HLW) and galleries (ILLLW) excavated at great depths in a lowpermeability host-rock (Callovo-Oxfordian argillite, ANDRA, 2005). Sealing of theses underground works to prevent potential pathways for water, gas and radionuclides migration is one of the key points to ensure the long-term safety of the repository.

Mixtures made up of bentonite powder and pellets are a candidate sealing material for deep underground radioactive waste repositories. In addition to their low permeability, high swelling capacity and high radionuclide migration retardation properties, powder/pellet mixtures have obvious operational advantages in terms of emplacement and reduction of the gaps between the rock and the seal. Once installed in the repository, powder/pellet mixtures will be submitted to coupled hydro-mechanical loadings comprising hydration due to the infiltration of pore water from the host rock and mechanical confinement resulting from the constrained volume condition imposed in the galleries. It is therefore essential to better understand their hydro-mechanical behaviour when assessing the overall repository safety.

In this context, and as part of the overall IRSN (French Institute for Radiological Protection and Nuclear Safety) R\&D program that provides scientific background for its expertise on disposal safety, the SEALEX (SEALing performance Experiments) project was launched to specifically focus on long-term performance of sealing systems. The SEALEX project is dedicated (i) to test the long-term hydraulic performance of sealing systems in normal conditions for different core compositions (mixtures composed of bentonite pellets with bentonite powder or of sand with bentonite powder) and for different configurations (pre- 
compacted bentonite blocks or bentonite compacted in situ), (ii) to quantify the impact of construction joints (also called technological voids) on the hydraulic properties of the sealing system, and (iii) investigate the concept of robustness by considering altered scenarios, such as an incidental decrease of the swelling pressure (for instance originating from the failure of the confining plugs). This project relies on a series of in situ experiments emplaced in IRSN's Underground Research Laboratory (URL) at Tournemire located in a Mesozoic sedimentary basin on the western edge of the French Causses (South France) (Mokni \& Barnichon., 2016). To install the experiments, horizontal boreholes $\left(0 \pm 2^{\circ}\right)$, with a $60 \mathrm{~cm}$ diameter and $540 \mathrm{~cm}$ long have been excavated from recent drifts (2008). Each experiment consists of a bentonitebased core mechanically confined at both ends corresponding to a generic seal mock-up except in terms of saturation that will be an artificial one carried out by water injection through porous filters installed at both ends of the core (Barnichon et al., 2012; Mokni \& Barnichon., 2016). Various materials are being considered as seals in the SEALEX project. The present work focuses on a mixture made up of MX80 bentonite powder and pellets with a proportion of $20 / 80$ in dry mass.

The use of high-density bentonite pellets combined with bentonite powder has also been proposed in Salo \& Kukkola (1989), Dereeper et al. (2001), Ab (2002). A characterisation of the fundamental properties of the MX80 bentonite pellets used in the Prototype Repository test is reported in Sugita et al. (2005). At a larger scale, a series of infiltration tests on a 50/50\% FoCa bentonite pellet/powder mixture compacted at different dry densities were performed by Imbert \& Villar (2006) to investigate the swelling capacity of the material.

It is well documented that the macroscopic behaviour of expansive soils is related to its microstructure (e.g. Alonso et al., 2011; Gens \& Alonso, 1992). For this reason, several investigations have been carried out on the microstructure of bentonite-based materials by using several methods including Mercury Intrusion Porosimetry (MIP) and/or Scanning 
Electron Microscopy (SEM) (Wang et al., 2012, 2013, 2014; Saba et al., 2014; Romero et al., 2011). There is less available data on pellets and powder-pellets mixtures. Hoffmann (2005) carried out MIP tests on samples of pellets of FEBEX bentonite under different conditions and observed a bimodal distribution on a single pellet with a dry unit mass $\rho_{d}=1.95 \mathrm{Mg} / \mathrm{m}^{3}$. For a non-compacted pellet mixture, a trimodal distribution was identified with two populations of pores corresponding to the intra and inter-aggregate pores and the third one related to the inter-pellet pores.

The microstructure investigation techniques require a preliminary dehydration of the samples, often carried out by freeze-drying. Due to the size of the sample investigated, these techniques provide local observations of a part of millimetric samples. These results may fruitfully be complemented by the use of X-ray computed microtomography ( $\mu$-CT), a non-destructive 3D technique that provides high-resolution observations of samples at a larger scale without any pre-treatment. The changes in microfabric during hydration under constant volume conditions of a $50 / 50$ pellet/powder mixture of FoCa clay at a dry unit weight of $1.36 \mathrm{Mg} / \mathrm{m}^{3}$ were observed by Van Geet et al. (2005) using $\mu$-CT. The significant changes of the pellet/powder mixture during hydration could be observed but the technique did not allow investigating the microstructure of an elementary pellet itself because the resolution of the images obtained was not enough in order to study the material at this scale.

This paper deals with an experimental program aiming to study the microstructural features of a pellet/powder mixture at various scales by using $\mu$-CT observations coupled to MIP and SEM investigations. This mixture will afterwards be used to develop a mock-up test in the laboratory, to simulate SEALEX in situ tests at reduced scale (1/10) by considering a column of $60 \mathrm{~mm}$ in diameter and $120 \mathrm{~mm}$ in height.

\section{Materials and methods}




\subsection{Materials}

The materials investigated are on the one hand the basic pellet made of MX80 bentonite and on the other hand a mixture of MX80 bentonite powder and pellets at a proportion of 20/80 in dry mass (Figure 1). The bentonite used comes from Wyoming, USA, and was provided by the Laviosa-MPC company under the commercial name Expangel (Expangel SP7 for pellets and Expangel SP32 for the powder). To make things clear, the name MX80 will however be used here. The MX80 bentonite has a high smectite content (80\%) with some inclusions of non-clayey minerals (see Table 1) and a cation exchange capacity (CEC) of $98 \mathrm{meq} / 100 \mathrm{~g}$. The major exchangeable cation is $\mathrm{Na}^{+}$, with a value of $52 \mathrm{meq} / 100 \mathrm{~g}$ (Table 2). The liquid limit is $560 \%$, the plastic limit is $53 \%$ and the unit mass is of $2.77 \mathrm{Mg} / \mathrm{m}^{3}$ (Saba et al., 2014, Table 3). Pellets were industrially produced in Laviosa-MPC company by instantaneously compacting a powder of MX80 bentonite in a mould of $7 \mathrm{~mm}$ of diameter and $7 \mathrm{~mm}$ of height (Laviosa Minerals). The fabrication was done at water content $w=5 \%-7 \%$ and at dry unit mass $\rho_{d}=$ $1.998 \mathrm{Mg} / \mathrm{m}^{3}-2.12 \mathrm{Mg} / \mathrm{m}^{3}$. Pellets were received in packages of $25 \mathrm{~kg}$ and stored in the laboratory at $20^{\circ} \mathrm{C}$. The pellet initial suction was measured in the laboratory with a chilled mirror dew point tensiometer (Decagon WP4), providing a value $s=132.4 \mathrm{MPa}$ at initial water content $w=7.25 \%$ (determined after drying in the oven at $105^{\circ} \mathrm{C}$ during $24 \mathrm{~h}$ ). More details about the initial properties of the pellets and the powder are presented in Table 3.

Figure 2 shows a typical pellet with a radius of $7.14 \mathrm{~mm}$ and a height of $7.27 \mathrm{~mm}$. It appears that the pellet has a quasi-cylindrical shape with two spherical poles on top and bottom. The lengths measured in the laboratory were larger than those just after the fabrication $(7 \mathrm{~mm})$, indicating swelling due to hydration in the course of storage. Indeed, higher water contents $(7.25 \%-6.69 \%)$ were measured on pellets located at the top of the bucket stored in the laboratory, compared to that located at the bottom $(6.06 \%-6.00 \%)$. 
The MX80 bentonite powder was produced by crushing pellets. The characteristics at initial state is presented in Table 3. Compared to the fabrication value of water content (between 5\% and $7 \%$ ), a value of $3.17 \%$ was found in the laboratory (after drying at $105^{\circ} \mathrm{C}$ for $24 \mathrm{~h}$ ) corresponding to an initial suction $s=190.9 \mathrm{MPa}$, measured with a chilled mirror dew point tensiometer (Decagon WP4). The grain size distribution of the powder, obtained by dry sieving is presented in Figure 3 together with the size of a pellet. The average diameter is $D_{50}=0.65 \mathrm{~mm}$.

\subsection{Testing procedures}

\section{Mercury intrusion porosimetry (MIP)}

The pore size distribution of both pellet and powder of MX80 bentonite was obtained on freeze dried samples using an Autopore IV 9500 mercury intrusion porosimeter (Micromeritics) that operates at a maximum pressure of $230 \mathrm{MPa}$. Instantaneous freezing was carried out by plunging small samples (a pellet of bentonite) in slush nitrogen $\left(-210^{\circ} \mathrm{C}\right)$ obtained by previously submitting it to vacuum (Delage et al., 1996). In such conditions, there is no nitrogen boiling around the samples when plunging them into nitrogen, resulting in an optimized quick freezing and good microstructure preservation. The pore size distribution was obtained assuming parallel, cylindrical nonintersecting pores of different radii, using the Autopore IV 9500 V1.09 standard software package. The total void ratio was obtained by standard methods and compared to the total volume of mercury intruded into the sample at a pressure of $230 \mathrm{MPa}$.

$X$-ray computed microtomography $(\mu-C T)$

The $\mu$-CT scans were carried out using an "Ultratom" microtomograph (RX Solutions, France). Images were reconstructed using the software Xact (RX Solutions). The source is a 
microfocus X-ray tube Hamamatsu L10801 and the imager is a Paxscan Varian 2520V (1960x1536 square pixels $127 \mu \mathrm{m}$ in size).

Several $\mu$-CT observations were carried out on a pellet of bentonite at initial state and on the powder/pellet MX80 bentonite mixture with a proportion of $80 / 20$ in dry mass. For a single pellet of bentonite, the X-ray source parameters were $80 \mathrm{kV}$ and $40 \mu \mathrm{A}$; the voxel size was $4.4 \mu \mathrm{m}$. The samples were scanned using 1440 projections equally spread on $360^{\circ}$. After reconstruction, 1292 horizontal slices were calculated (16bit images; 1644x1292 pixels). For the powder/pellet mixture, the X-ray source parameters were $100 \mathrm{kV}$ and $25 \mu \mathrm{A}$; the voxel size was $59 \mu \mathrm{m}$. The mixture was scanned using 2880 projections in helical mode and after reconstruction 2472 horizontal slices were obtained (16 bit images, 1735x1735 pixels).

\section{Scanning electron microscopy (SEM) and Energy-Dispersive X-ray spectroscopy (EDS)}

SEM combined to EDS was performed in order to carry out a chemical characterization of a pellet of bentonite at initial state. Instantaneous freezing was carried out by plunging the samples in slush nitrogen $\left(-210^{\circ} \mathrm{C}\right)$. After freeze-drying, the pellet of bentonite was carefully cut at mid-height, separating the upper and the lower poles. Once cut, the specimens were immerged into a resin and polished with abrasive papers with decreasing fineness from grade 800 to 4000 in order to obtain a smooth surface. Finally, the samples were metallized under vacuum with gold and palladium. Observations in conventional SEM require a high vacuum condition to allow a precise focusing of the incident electrons on the sample and to prevent the emitted electrons from interacting with the atmosphere.

\subsection{The pellet/bentonite mixture}

Two SEALEX performance tests with core made of MX80 bentonite powder/pellets (20/80) have been installed in Tournemire URL, in February and October 2013, to investigate the impact of core composition and conditioning on the long term performance of sealing 
systems. To ensure the feasibility of injecting within a large diameter and compacting in situ a seal made of pellet/powder mixture so as to obtain a reasonably homogeneous core with the target dry unit mass of $1.49 \mathrm{Mg} / \mathrm{m}^{3}$, a series of preliminary full scale mock up tests were carried out using a plastic tube with transparent windows to allow the observation of the distribution of the mixture within the emplacement borehole. The bentonite was introduced by means of an auger conveyor measuring $5 \mathrm{~m}$ in length and $60 \mathrm{~mm}$ in outer diameter. The auger measures $50 \mathrm{~mm}$ in diameter and is driven by a $1.5 \mathrm{~kW}$ geared motor. The tube features a loading hoper and has a flanged connection in its midpoint, so that despite its length it can be easily mounted in the gallery with its back end already inserted in the borehole, as the auger inside is flexible.

It is however important to prepare an homogeneous powder/pellet MX80 bentonite mixture at the required target dry unit mass $\left(1.49 \mathrm{Mg} / \mathrm{m}^{3}\right)$ because the dry unit mass governs both the saturated permeability $\left(k_{w}\right)$ and the swelling pressure of the mixture (Saba et al., 2014; Hoffmann et al., 2007). In this study, the challenge was to obtain a reasonably homogeneous powder/pellet mixture to be placed in a reduced scale mock-up test of the SEALEX in situ tests. This mock-up test is planned to be carried out at a scale of 1/10 of the SEALEX tests, corresponding to a cylinder of $60 \mathrm{~mm}$ in diameter and $120 \mathrm{~mm}$ in height.

Three protocols were considered aiming at identifying the one that provides the best homogeneity. The first protocol consisted in filling the cell by packets corresponding to one layer of pellets spread over the base of the $60 \mathrm{~mm}$ diameter cylinder and by adding the corresponding amount of powder ( $80 \%$ pellets and $20 \%$ powder). The second protocol was comparable but involved two layers of pellets. Finally, the third protocol consisted in filling a quantity of pellets corresponding to three layers, but that has been previously mixed with the powder. 


\section{Results}

\subsection{X-ray computed microtomography}

208

209

210

\section{Case of Pellet}

Further information about the microstructure of a pellet of bentonite at initial state (suction $s$ $=132.4 \mathrm{MPa}$, water content $w=7.25 \%$ and dry unit mass $\rho_{d}=2.12 \mathrm{Mg} / \mathrm{m}^{3}$ ) was obtained using $\mu$-CT observations.

Figure 4 and Figure 5 show horizontal and vertical slices, respectively, taken at different positions as indicated in the photo of the pellets presented on top left in the figures. Grey levels depend on the density and atomic number of the components, with darker grey levels typically corresponding to lower densities and black zones to voids. Several higher density elements (light grey levels) are observed in both cases. Several cracks are identified in the sections located in the upper part of the pellet (horizontal sections I and II, and vertical sections I, II and III). It can be deduced from Figure 4 that they coincide with the upper spherical part, close to the contact with the cylindrical section. Such fissures are not observed on the same zone at the bottom of the pellet.

Further information about the fissure network is obtained by a 3D rendering of the surfaces defined by the cracks within a region of interest of the pellet at initial state presented in Figure 6. Cracks are defined as the voxels with a grey level below some threshold. It is observed that crack networks are located on both the upper and bottom part of the pellet; however, as it was revealed by horizontal and vertical slices, there are more cracks in the upper part. The 3D rendering was performed by means of the Avizo image analysis software.

Further investigation on a single pellet and on the respective distribution of pellets and powder within the mixture was done by means of image analysis. In a first step, a region of interest (ROI) in the sample was selected (Figure 7). Then, a segmentation of the image was 
made to separate the voids from the other phases (i.e. the pellets and the powder grains). This step was completed using the ImageJ image analysis software. This method is a variation of the IsoData algorithm (Ridler \& Calvard, 1978), an iterative procedure that divides the image into an object and a background by adopting an initial threshold. Then the averages of the pixels at or below the threshold and pixels above are computed, the threshold is incremented and the process is repeated until the threshold is larger than the composite average. Figure 7 shows the initial state with the selected ROI (a) and the segmented image (b). It is noted that such a procedure does not give access to an accurate evaluation of the actual total porosity of the sample, as the result strongly depends on the selected threshold, is strongly sensitive to partial volume effects and other image artefacts, and does not allow to detect the smaller pores. It provides however a way to characterize, at least qualitatively, the spatial distribution of the larger voids within the sample.

An investigation of the porosity was conducted on a single pellet of bentonite with this approach. The porosity was calculated for each horizontal slice obtained by $\mu$-CT observations by dividing the number of black voxels (below some threshold, corresponding to voids) by the total number of voxels within the pellet. Figure 8 and Figure 9 present the calculated values of void ratio for horizontal and vertical sections respectively. It is confirmed from Figure 8 that the value of void ratio increases at the upper part of the pellet (for a level higher than $5 \mathrm{~mm}$ ) because of the presence of the fissures. In Figure 9 (calculated void ratio for each vertical section), the highest values of void ratio are located at both edges and in the centre of the pellet. Note that this porosity corresponds to that detected by image analysis with a resolution of $4.4 \mu \mathrm{m} /$ voxel and for a particular choice of grey level threshold; hence, it provides a first evaluation of the porosity associated with the cracks (see for instance the 3D representation of the fissure network of Figure 6). 
257 The homogeneity of the specimens obtained by using each of the three protocols was examined by using X-ray computed microtomography, the results of which are presented in Figure 10. Observation of Figure 10a shows that the first protocol (1 layer) provided a reasonably good homogeneity of the mixture, with regular scattering of the powder grains within the pores located between the pellets. Several voids between the pellets are however observed at the top of the sample. Inspection of Figure 10b shows that the homogeneity is not ensured with the second protocol (2 layers) with much more inter-pellets pores that are not filled with powder, particularly in the peripheral part of the specimen. Note also the presence of large inter-pellets voids completely filed with powder, in the middle of the sample at $1 / 3$ of the height. The same problem is observed with the third protocol (Figure 10c). The target dry unit mass $\left(\rho_{d}=1.49 \mathrm{Mg} / \mathrm{m}^{3}\right)$ was obtained with the first protocol only, while a unit mass of $\rho_{d}=1.41 \mathrm{Mg} / \mathrm{m}^{3}$ and $1.43 \mathrm{Mg} / \mathrm{m}^{3}$ is found for the second and third protocols respectively.

An investigation of the porosity was conducted on the three protocols in the same way as detailed previously for a single pellet of bentonite. To this end, the porosity was estimated for each horizontal slice obtained by $\mu$-CT observations, using the same threshold for all slices. Figure 11 presents the evolution of the obtained porosity along the height of the sample for the three protocols. One can observe an oscillation of the value of porosity for all three protocols. In the first one, the minimum and maximum void ratios are 0.18 and 0.63 respectively. Oscillations are more remarkable and they correspond to one layer of pellets. In the second protocol, the minimum and maximum void ratio values are 0.15 and 0.33 respectively, oscillating around a value of 0.2 . Finally, for the third protocol, void ratio goes from 0.08 to 0.55 , and the oscillations correspond to three layers of pellets. 
281 Taking into account the target dry density, the homogeneity observed in Figure 10 and the

282

283 data of image analysis, the first protocol should be selected in order to prepare the pellet/powder mixture samples of MX80 bentonite. Note however that the best result corresponds to the second protocol according to the image analysis, because the values of void ratio oscillate around a value of 0.2 for all the sections. This low fluctuation along the vertical direction of the apparent average porosity within a section does however not reflect the strong heterogeneity of the pore distribution within a section, which is observed in the vertical slice represented in Figure 12b. Furthermore, the target dry density $\left(1.49 \mathrm{Mg} / \mathrm{m}^{3}\right)$ was only obtained with the first protocol.

\subsection{Mercury intrusion porosimetry}

Figure 12 shows the results of MIP tests carried out on a pellet $(w=6.7 \%, s=138.4 \mathrm{MPa})$ and on the bentonite powder $(w=3.1 \%, s=190.9 \mathrm{MPa})$. The cumulative curve (Figure 12a) shows that the final value of intruded mercury void ratio of the pellet $(e=0.23)$ is lower than its total void ratio $\left(e_{T}=0.34\right)$, indicating a significant porosity with an average diameter smaller than $5.5 \mathrm{~nm}$, corresponding to the maximum mercury pressure applied (230 MPa). This is well known for compacted smectite (Lloret et al., 2003; Delage et al., 2006; Ridley et al., 2010).

A typical bimodal porosity distribution is observed for the bentonite powder, with an intruded void ratio of 0.9 at maximum mercury pressure $(230 \mathrm{MPa})$. Actually, this void ratio is conditioned by the isotropic compression exerted by the mercury prior to penetrating the powder. The density function curve indicates that this penetration occurs at an average entrance diameter of $207 \mu \mathrm{m}$ between powder grains with an average diameter of $0.65 \mathrm{~mm}$. 
This configuration is not far from the standard ratio between the diameter of spherical grains and the inter-grains pores of their dense assembly, known to be close to $1 / 3$. The second pore population is defined by an average entrance of $16.6 \mathrm{~nm}$, to relate to a suction of $190.9 \mathrm{MPa}$ of the powder.

The PSD curve of the pellet has a population of micro-pores quite comparable with an average entrance diameter of $13.3 \mathrm{~nm}$, recalling that the powder was obtained from crushed pellets. Another less clearly defined porosity is observed with an average entrance diameter of $5 \mu \mathrm{m}$, that will be described in more details later on. The intruded void ratio represents $67.6 \%$ of the total void ratio. The void ratio of the population of large pores represents around $5.6 \%$ of the total void ratio.

\subsection{EDS characterisation}

Figure 13 presents SEM photos along with the corresponding EDS chemical analysis of the inclusions of different minerals observed within the pellet of bentonite. These inclusions correspond to the high density elements found by $\mu$-CT observations and are included in the mineralogical composition of the MX80 bentonite given in Table 1. These minerals are identified based on the chemical composition detected by EDS: a high concentration of silicon indicate an inclusion of quartz (see the two inclusions observed in Figure 13a and b); a concentration in sulphur/iron indicate a pyrite inclusion (see Figure 13c). Note that the dimensions of these inclusions are significant $(137.3 \mu \mathrm{m}$ and $70.4 \mu \mathrm{m}$ for the quartz inclusions) compared to the size of the pellet. An inclusion of calcite is also observed in Figure 14, which was not identified in the X-ray diffractometer (XRD) analyses of MX80 bentonite (Table 1).

\section{Discussion}


Most of the investigations carried out up to now on bentonite-based materials have been based on the use of MIP and SEM (e.g. Saba et al., 2014; Wang et al., 2013, 2014; Romero et al., 2011). These techniques, that require preliminary dehydration of the samples and that concern specimen volumes smaller than about $1 \mathrm{~cm}^{3}$ can be fruitfully complemented by more recent techniques like X-ray computed microtomography (Van Geet et al., 2005) that investigate specimens at larger scale and do not require any preliminary treatment.

In this paper, the microstructure of a pellet of bentonite at its initial state was studied by the pore size distribution curve, obtained by MIP technique. An expected bimodal distribution was obtained, where, theoretically, micro-pores correspond to voids inside an aggregate of bentonite and macro-pores are related to pores between aggregates. The difference between the final value of intruded mercury and the total void ratio in the cumulative curves (Figure 12) suggests that there are several void sizes which cannot be filled by mercury. These voids correspond to pores with a diameter smaller than $5.5 \mathrm{~nm}$ and large fissures identified by $\mu$-CT observations. Consequently, it would be convenient to complete this MIP results with nitrogen gas adsorption (BET) technique in future investigations. The PSD curve of the powder of bentonite at its initial state was also obtained. The micro-pores of a single pellet and that of the powder are similar. For the macro-pores, the mean entrance is much larger than the obtained value for a pellet of bentonite. This value corresponds to the voids between grains of bentonite.

X-ray computed microtomography $(\mu-\mathrm{CT})$ observations revealed fissures at the upper part of the pellet of bentonite (sections I and II presented in Figure 4 and sections I, II and III in Figure 5) as well as non-swelling elements which could influence the swelling potential of the material. For the section I in Figure 4, located at the upper spherical pole of the pellet, there is a predominant grey level with some deviations. At the border of the section an element of 
high density (white) is distinguished. Furthermore, several fissures are observed, confirming that the pellet had already swollen during storage at the laboratory.

For section II (Figure 4), located at the upper part of the pellet, more fissures are observed at the edge of the pellet, as well as elements of high density (white pixels observed everywhere). Based on those observations, the following remarks could be made: (i) pellets swell from the border to the centre (layers in contact with the atmosphere will swell, inducing fissures) and (ii) fissures observed at section I (Figure 4), located at the upper spherical pole of the pellet, could be due to the fabrication process combined to swelling.

For sections III and IV (Figure 4), located at the medium level and the lower spherical pole respectively, no more fissures are observed, but several elements of high density can still be identified. This suggests that the internal structure of a pellet of bentonite is not homogeneous. In addition to the existence of high density elements, different grey levels in the clayey part of the pellet are observed. The same conclusions can be extracted from the vertical sections I, II and III (Figure 5).

\section{Conclusion}

The $\mu$-CT investigation of the microstructure of a pellet of bentonite provided interesting complementary features that could not be identified by MIP and SEM observations. Heterogeneous features were observed in the internal structure of the pellet, consisting in a heterogeneous density distribution of the clay minerals and in the presence of several high density elements. Furthermore, several fissures were observed at the upper pole of the pellet. This heterogeneity of a single pellet was confirmed by SEM and EDS observations, where several inclusions of non-swelling elements were observed (quartz, pyrite and calcite). The 
dimensions of these inclusions are not negligible, indicating that this could have an influence on the swelling potential of the pellet.

The MIP tests carried out on a pellet and powder of MX80 bentonite revealed some similarity between both materials, which is not surprising since the powder was fabricated by crushing pellets of bentonite. This similarity consisted on a double porosity and a comparable value of the mean size diameter of the micro-pores. The complementary information provided by $\mu$ CT observations evidenced that macro-pores found by MIP results are due to voids between fissures observed at the upper pole of the pellet and cracks observed at the top and the bottom. A difference is observed when comparing the final value intruded by mercury and the total void ratio in the cumulative curves, which corresponds to micro-pores with a diameter smaller than $5.5 \mathrm{~nm}$ and large fissures observed by $\mu$-CT observations on the upper part of the pellet. Thus, in order to have a good understanding of the microstructure of bentonite-based materials, it is important to carry out these complementary observations together with MIP, SEM + EDS results. The $\mu-C T$ observations obtained from a pellet/powder bentonite mixture revealed a heterogeneous initial distribution of both materials within the sample. Thus, it can be concluded that this mixture is characterized by a double heterogeneity: at a microscopic level, a heterogeneous structure inside a pellet of bentonite, and at a macroscopic level, a heterogeneous distribution of pellets and powder. The investigation of this initial heterogeneity is important to understand the long-term evolution of the sealing for larger scale systems. Initially, the system is characterized by a heterogeneous distribution of dry density, so an anisotropic swelling will be attended. Future investigations should be conducted in order to study the heterogeneity of the material at the final state. 


\section{References}

ANDRA, 2005, Dossier 2005 argile-Tome-evolution phénoménologique du stockage géologique.Rapport Andra no. C.RP.ADS.04.0025, France.

N. Mokni \& J:D Barnichon, Hydro-mechanical analysis of SEALEX in situ tests- Impact of technological gaps on long term performance of repository seals. Engineering Geology, 205, pp. 81-92.

Alonso, E.E., Romero, E. \& Hoffmann, C., 2011. Hydromechanical behaviour of compacted granular expansive mixtures: experimental and constitutive study. Géotechnique, 61(4), pp.329-344.

Barnichon, J.D., Dick, P. \& Bauer, C., 2012. The SEALEX in situ experiments : Performance tests of repository seals. Harmonising Rock Engineering and the Environment - Qian and Zhou (eds) Taylor and Francis Group, London, pp.1391-1394.

Delage, P. et al., 2006. Ageing effects in a compacted bentonite: a microstructure approach. Géotechnique, 56(5), pp.291-304.

Delage, P. et al., 1996. Microstructure of a compacted silt. Canadian Geotechnical Journal, 33, pp.150-158.

Dereeper, B. et al., 2001. Pellets/powder mixture of bentonite for backfill and sealing of HLW repositories. Adadchi, K., Fukue, M. (Eds.), Clay Science for Engineering. Balkema, Rotterdam, pp.487-490.

Van Geet, M., Volckaert, G. \& Roels, S., 2005. The use of microfocus X-ray computed tomography in characterising the hydration of a clay pellet/powder mixture. Applied Clay Science, 29(2), pp.73-87.

Gens, A. \& Alonso, E.E., 1992. A framework for behavior of unsaturated expansive clays. Canadian Geotechnical Journal, 29, pp.1013-1032.

Hoffmann, C., Alonso, E.E. \& Romero, E., 2007. Hydro-mechanical behaviour of bentonite pellet mixtures. Physics and Chemistry of the Earth, 32(8-14), pp.832-849.

Hoffmann Jauge, C.A., 2005. Caracterización hidromecánica de mezclas de pellets de bentonita. Estudio experimental y constitutivo. Available at: http://www.tdx.cat/handle/10803/6235 [Accessed July 13, 2015]. 
Imbert, C. \& Villar, M.V., 2006. Hydro-mechanical response of a bentonite pellets/powder mixture upon infiltration. Applied Clay Science, 32(3-4), pp.197-209.

Lloret, A. et al., 2003. Mechanical behaviour of heavily compacted bentonite under high suction changes. , (1), pp.27-40. Available at: http://dx.doi.org/10.1680/geot.53.1.27.37258.

Management Swedish Nuclear Fuel and Waste, 2002. Äspö Hard Rock Laboratory. Annual Report 2001.

Ridler, T.W. Calvard, S., 1978. Picture Thresholding Using an Iterative Slection Method. IEEE Transactions on Systems, Man and Cybernetics, 8(8), pp.630-632.

Ridley, a., Zdravkovic, L. \& Monroy, R., 2010. Evolution of microstructure in compacted London Clay during wetting and loading. Géotechnique, 60(2), pp.105-119.

Romero, E., Della Vecchia, G. \& Jommi, C., 2011. An insight into the water retention properties of compacted clayey soils. Géotechnique, 61(4), pp.313-328.

Saba, S., Romero, E., et al., 2014. Hydro-mechanical behaviour of bentonite-sand mixture used as sealing materials in radioactive waste disposal galleries. Université de Paris Est.

Saba, S., Barnichon, J.-D., et al., 2014. Microstructure and anisotropic swelling behaviour of compacted bentonite/sand mixture. Journal of Rock Mechanics and Geotechnical Engineering, 6(2), pp.126-132. Available at: http://linkinghub.elsevier.com/retrieve/pii/S1674775514000158.

Salo, J.-P. \& Kukkola, T., 1989. Bentonite pellets, an alternative buffer material for spent fuel canister deposition holes. Workshop "Sealing of Radioactive Waster Repositories". Braunschweig.

Sugita, Y., Chijimatsu, M. \& Suzuki, H., 2005. Fundamental properties of bentonite pellet for Prototype Repository Project. In: Alonso, E. E., Ledesma, A. (Eds.), Advances in Understanding Engineered Clay Barriers. A. A. Balkema Publishers, Leiden, pp.293299.

Wang, L., 2012. Micromechanical experimental investigation and modelling of strain and damage of argillaceous rocks under combined hydric and mechanical loads. Available at: http://pastel.archives-ouvertes.fr/pastel-00794900.

Wang, Q. et al., 2013. Hydraulic conductivity and microstructure changes of compacted bentonite/sand mixture during hydration. Engineering Geology, 164, pp.67-76. Available at: http://dx.doi.org/10.1016/j.enggeo.2013.06.013.

Wang, Q. et al., 2014. Time- and density-dependent microstructure features of compacted bentonite. Soils and Foundations, 54(4), pp.657-666. 


\section{List of Tables}

Table 1. Results from the X-ray diffractometer (XRD) of the MX80 bentonite. The results are expressed as a percent of the total mass (Laviosa Minerals SpA) Table 2. Cation exchange capacity (CEC) and original exchangeable cations of the MX80 bentonite (Laviosa Minerals SpA) 20 Table 3. Initial properties and conditions of pellets and powder of bentonite ......................... 20 Table 4. Properties of powder of MX80 bentonite.

\section{List of figures}

Figure 1. Mixture of MX80 bentonite powder and pellets with a proportion of 20/80 in dry mass...... 21

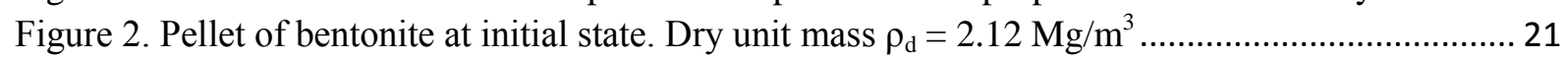

Figure 3. Grain size distribution of the MX80 bentonite powder....................................................... 21 Figure 4. X-ray computed microtomography $(\mu-\mathrm{CT})$ observations - horizontal sections - of a pellet of bentonite at its initial state.

Figure 5. X-ray computed microtomography $(\mu-\mathrm{CT})$ observations - vertical sections - of a pellet of bentonite at initial state.

Figure 6.3D rendering of a pellet of bentonite at initial state (a) and of the crack network in a region of interest (b).

Figure 7. Horizontal slice with the selected ROI (a) and segmented image (b)................................. 23

Figure 8. Evolution of the void ratio with height of a pellet of bentonite at initial state (Y direction horizontal sections).

Figure 9. Evolution of the void ratio of a pellet of bentonite at initial state (X direction - vertical sections).

Figure 10. Vertical cross section of X-ray computed microtomography images of a mixture of powder/pellets of bentonite with a proportion of 20/80 in dry mass obtained by three different protocols. (a) First protocol of mixture, (b) Second protocol and (c) third protocol. Figure 11. Evolution of the void ratio along height of a pellet/powder MX80 bentonite mixture (80/20) fabricated by three protocols. Figure 12. Cumulative porosity curve (a) and derivative curve (b) for a pellet and powder of bentonite at their initial state. Figure 13. SEM pictures taken on a pellet of bentonite at its initial state (132.38 MPa of suction) + EDS results. Mineral inclusions of quartz (a, b) and pyrite (c). Dry unit mass $\rho_{d}=2.12 \mathrm{Mg} / \mathrm{m}^{3} \ldots \ldots \ldots .27$ Figure 16. SEM picture taken on a pellet of bentonite at its initial state (132.38 MPa of suction) + EDS results. Mineral inclusion of calcite. Dry unit mass $\rho_{\mathrm{d}}=2.12 \mathrm{Mg} / \mathrm{m}^{3}$ 
Table 1. Results from the X-ray diffractometer (XRD) of the MX80 bentonite. The results are expressed as a percent of the total mass (Laviosa Minerals SpA)

\begin{tabular}{l|l} 
Mineral & $\%$ of the total mass \\
\hline Pyrite & $<1 \%$ \\
Smectite & $80 \%$ \\
Albite & $2 \%$ \\
Anorthite & $8 \%$ \\
Quartz & $4 \%$ \\
Muscovite & $4 \%$
\end{tabular}

Table 2. Cation exchange capacity (CEC) and original exchangeable cations of the MX80 bentonite (Laviosa Minerals SpA)

\begin{tabular}{l|l} 
Property \\
\hline CEC Capacity & $98 \mathrm{meq} / 100 \mathrm{~g}$ \\
Na conversion & $52 \mathrm{meq} / 100 \mathrm{~g}$ \\
K conversion & $1.2 \mathrm{meq} / 100 \mathrm{~g}$ \\
Mg conversion & $10 \mathrm{meq} / 100 \mathrm{~g}$ \\
Ca conversion & $37 \mathrm{meq} / 100 \mathrm{~g}$
\end{tabular}

Table 3. Initial properties and conditions of pellets and powder of bentonite

\begin{tabular}{l|c|c} 
& Pellet & Powder \\
\hline Initial suction, $s_{0}$ & $132.4 \mathrm{MPa}$ & $190.9 \mathrm{MPa}$ \\
Initial water content, $w_{0}$ & $7.25 \%$ & $3.17 \%$ \\
Initial dry density, $\rho_{0}$ & $2.12 \mathrm{Mg} / \mathrm{m}^{3}$ & \\
Initial porosity, $\varphi_{0}$ & 0.25 & \\
Unit mass of bentonite particles, $\rho_{s}{ }^{*}$ & \multicolumn{2}{|c|}{$2.77 \mathrm{Mg} / \mathrm{m}^{3}$}
\end{tabular}

*(Saba et al., 2014)

Table 4. Properties of powder of MX80 bentonite

Atterberg limits

\begin{tabular}{l|l}
\hline Liquid limit, LL & $560 \%$ \\
Plasticity limit, PL & $62 \%$ \\
Shrinkage index, SI & $498 \%$
\end{tabular}




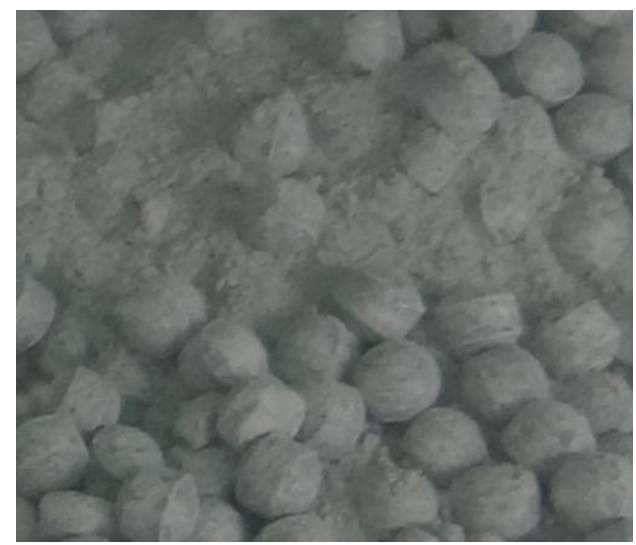

521 Figure 1. Mixture of MX80 bentonite powder and pellets with a proportion of 20/80 in dry mass.

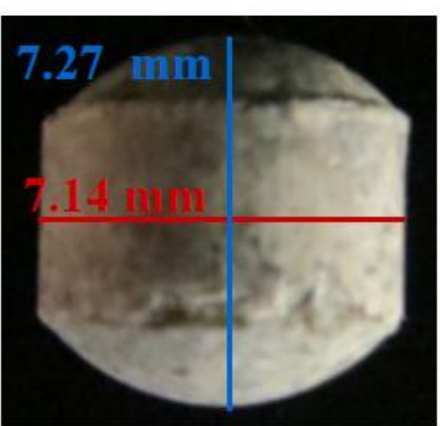

Figure 2. Pellet of bentonite at initial state. Dry unit mass $\rho_{d}=2.12 \mathrm{Mg} / \mathrm{m}^{3}$

526

527

528 529

530

531

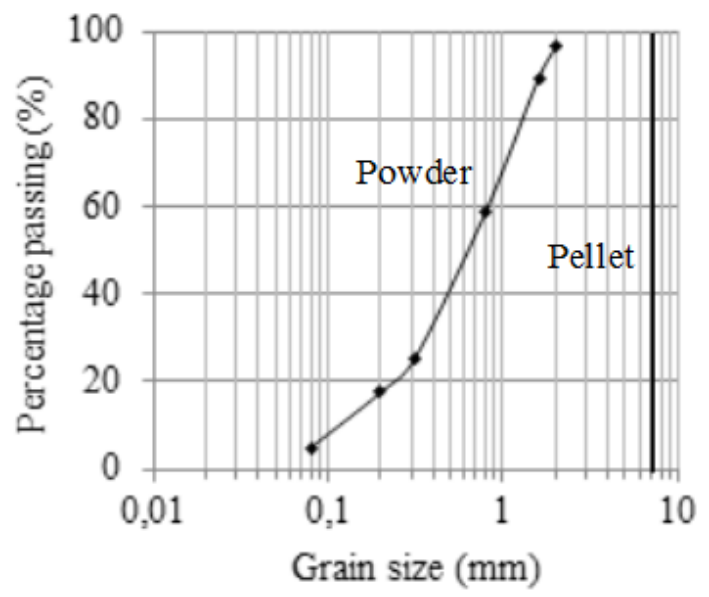

Figure 3. Grain size distribution of the MX80 bentonite powder. 


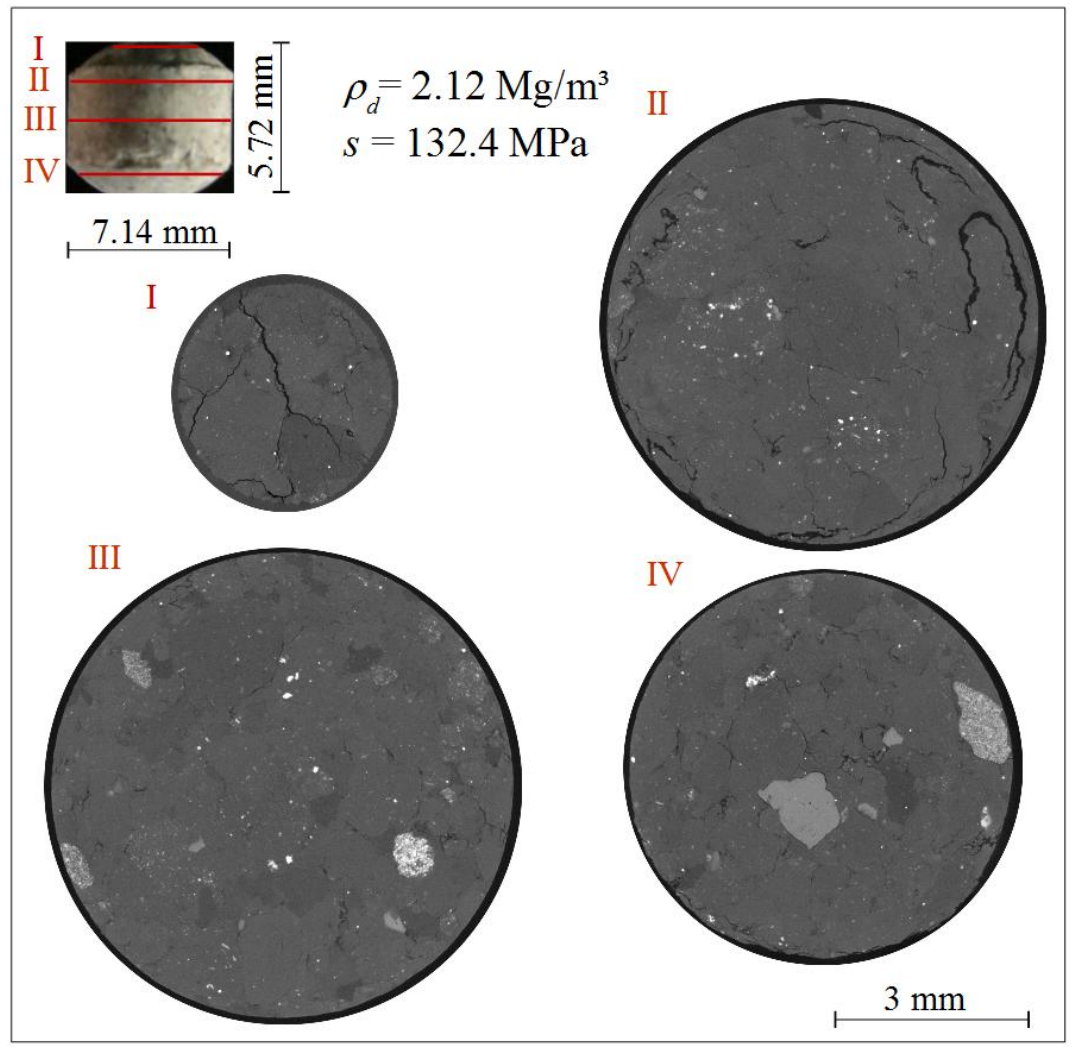

533 534

535

$$
\begin{aligned}
& \rho_{d}=2.12 \mathrm{Mg} / \mathrm{m}^{3} \\
& s=132.4 \mathrm{MPa}
\end{aligned}
$$
pellet of bentonite at its initial state.

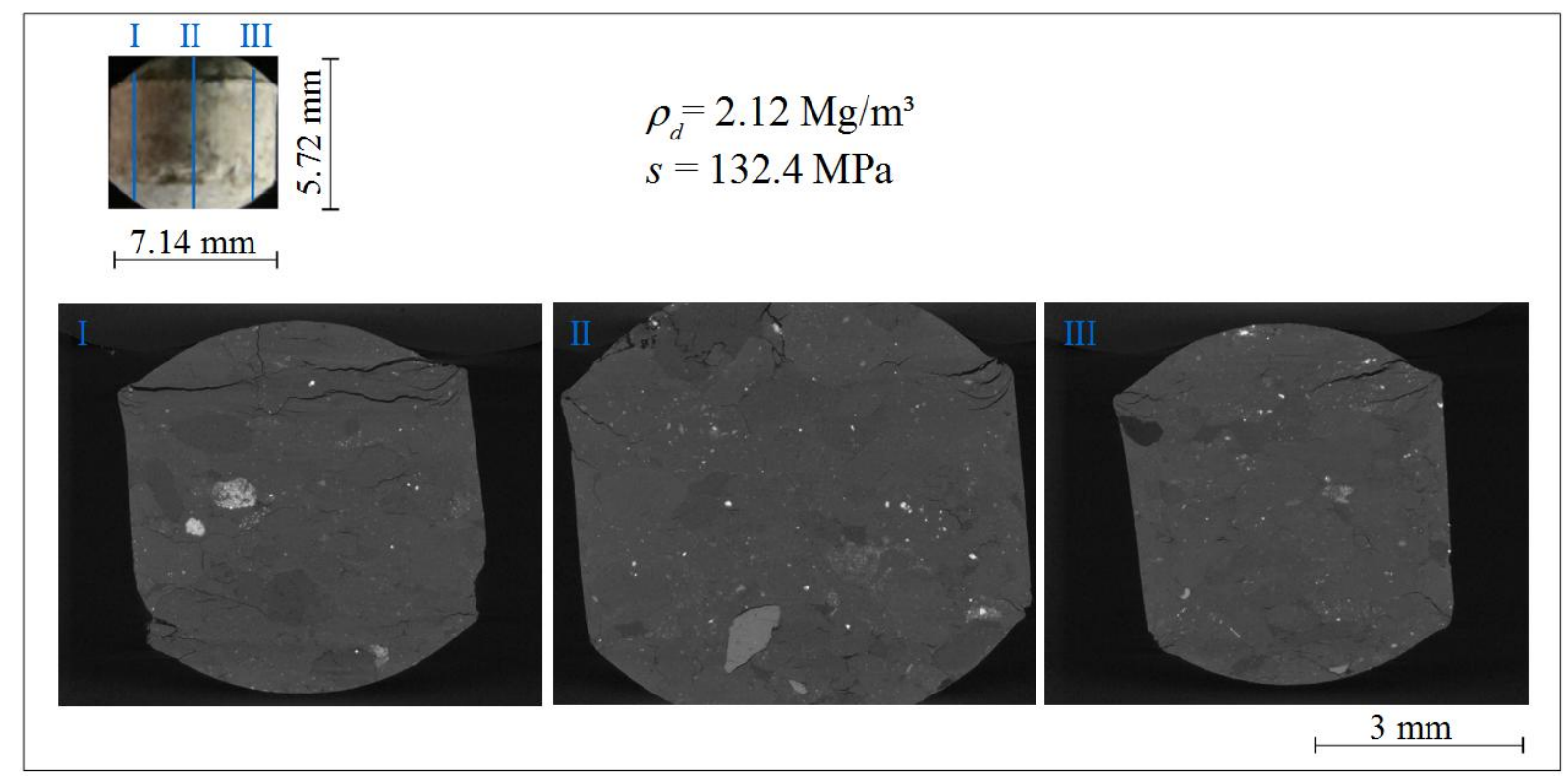

Figure 5. X-ray computed microtomography ( $\mu$-CT) observations - vertical sections - of a pellet of bentonite at initial state. 
(a)

(b)

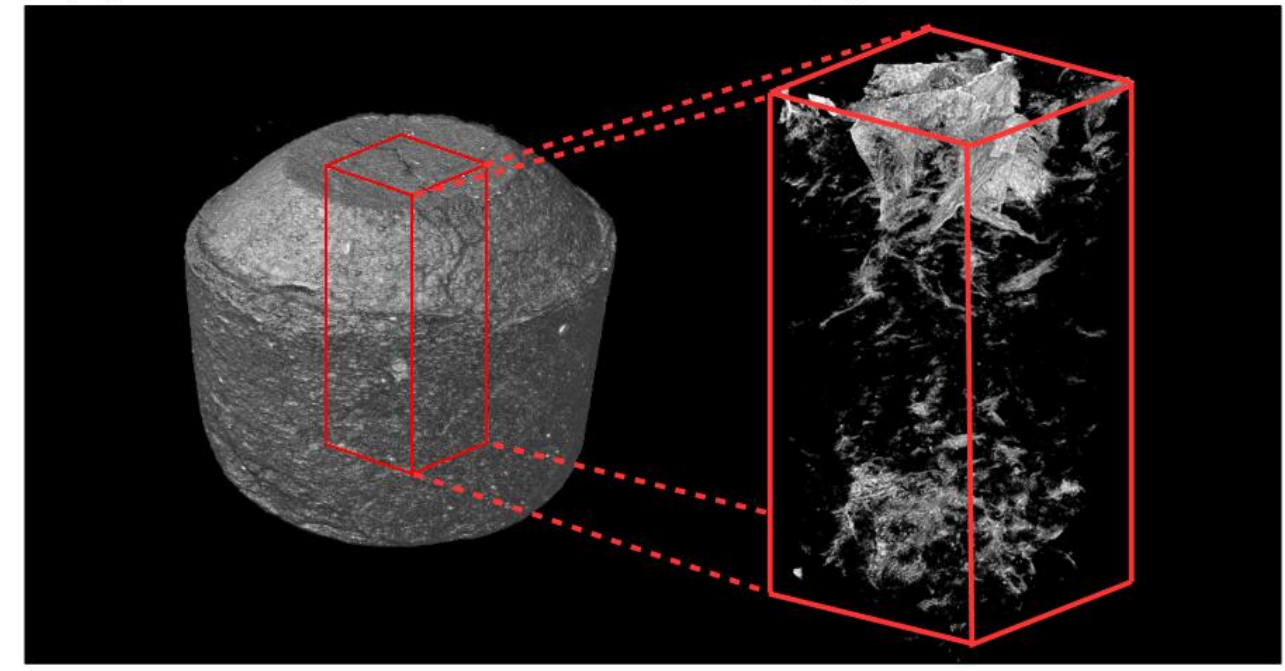

(a)

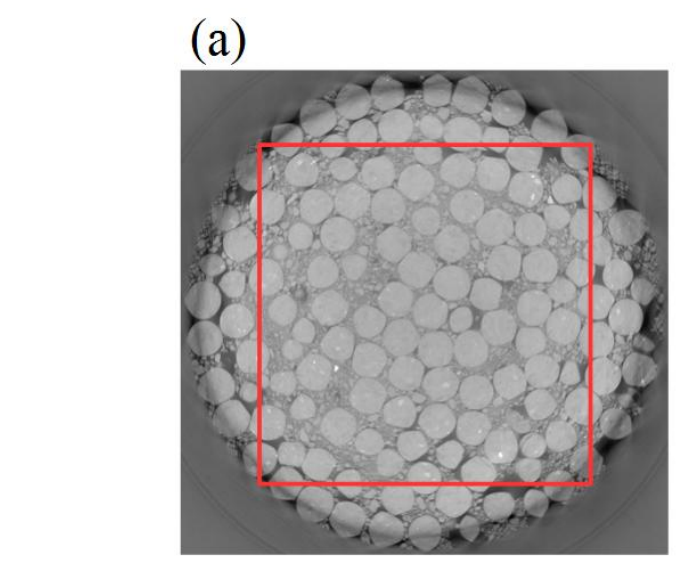

Figure 6. 3D rendering of a pellet of bentonite at initial state (a) and of the crack network in a region of interest (b).

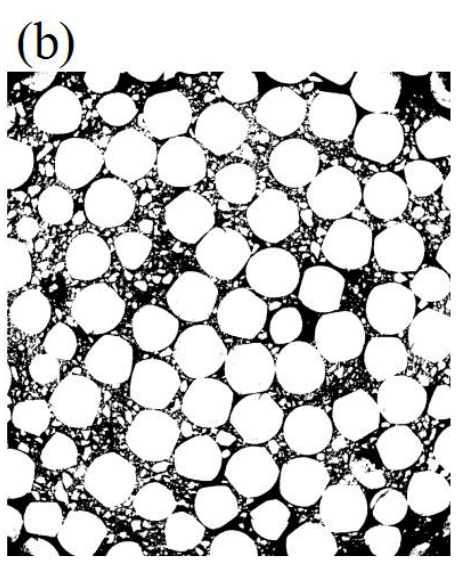

Figure 7. Horizontal slice with the selected ROI (a) and segmented image (b). 


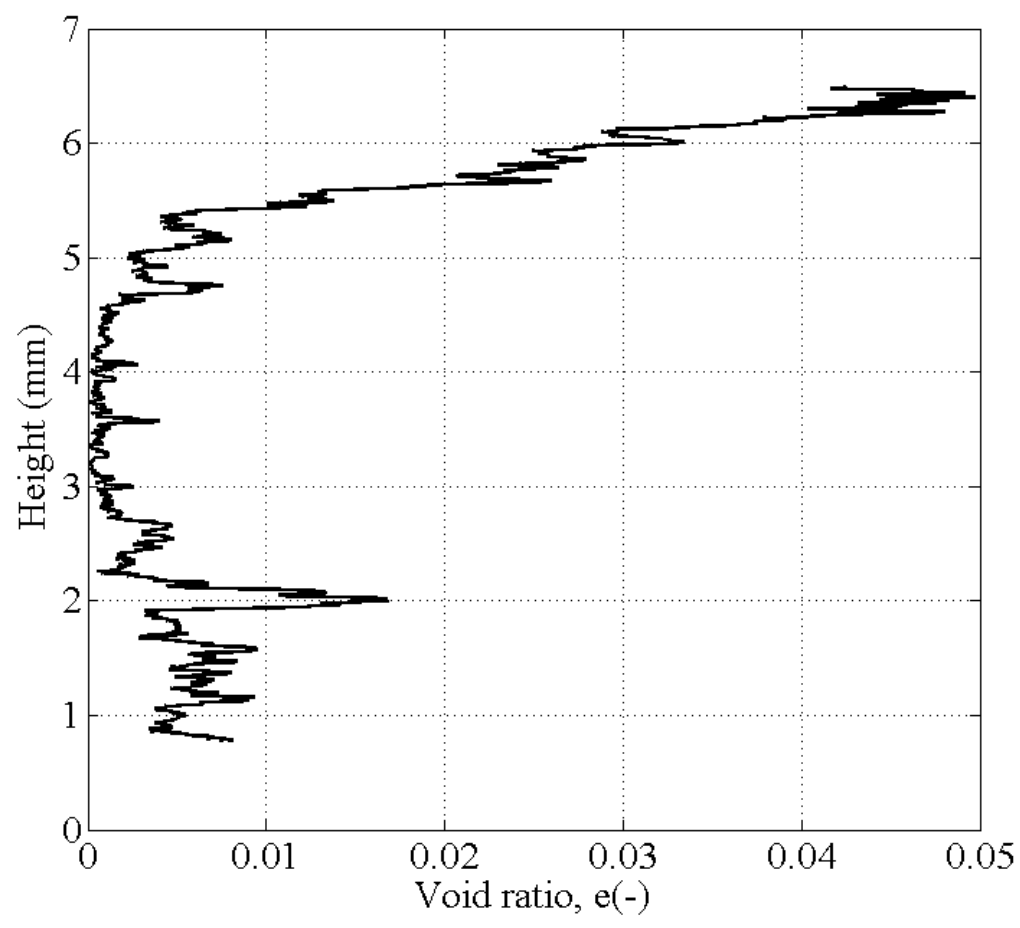

547 Figure 8. Evolution of the void ratio with height of a pellet of bentonite at initial state (Y direction - horizontal sections).

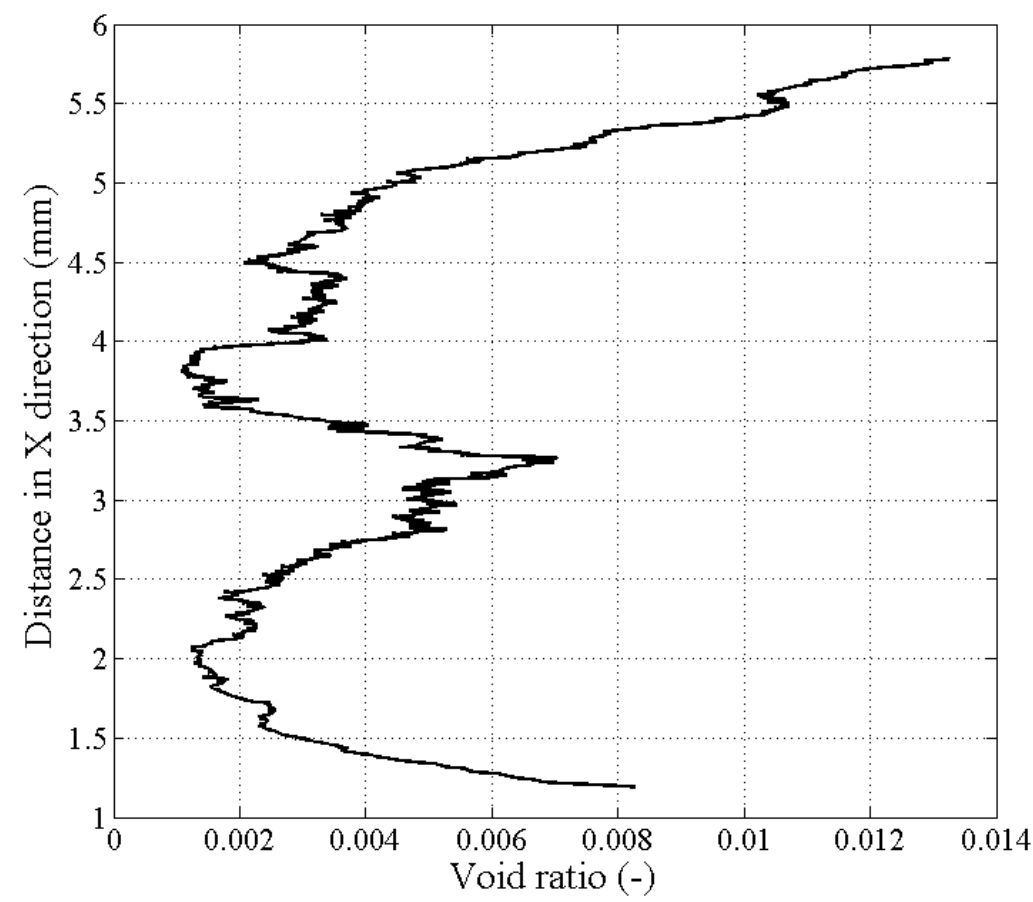

Figure 9. Evolution of the void ratio of a pellet of bentonite at initial state (X direction vertical sections). 
(a)

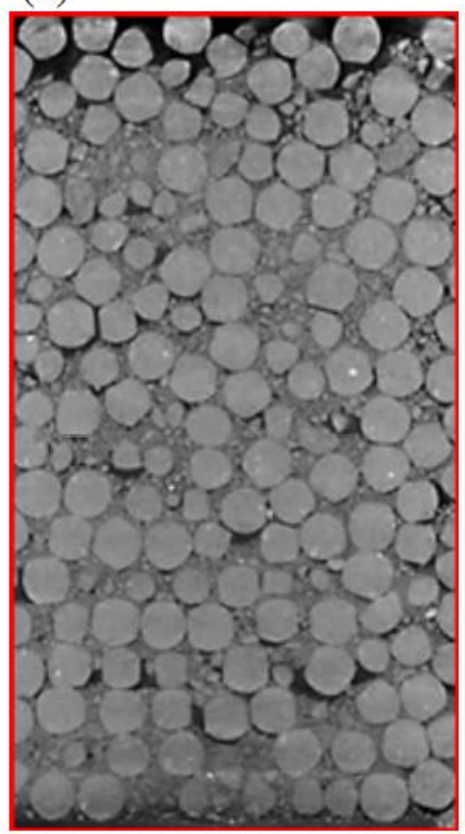

(b)

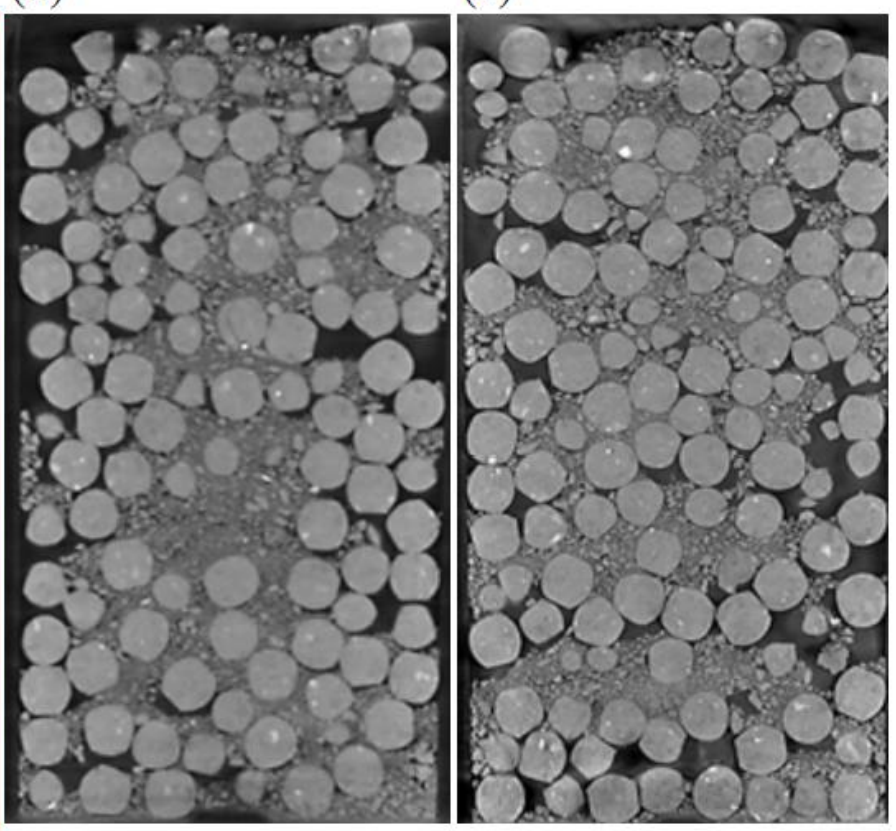

Figure 10. Vertical cross section of X-ray computed microtomography images of a mixture of powder/pellets of bentonite with a proportion of 20/80 in dry mass obtained by three different protocols. (a) First protocol of mixture, (b) Second protocol and (c) third protocol.

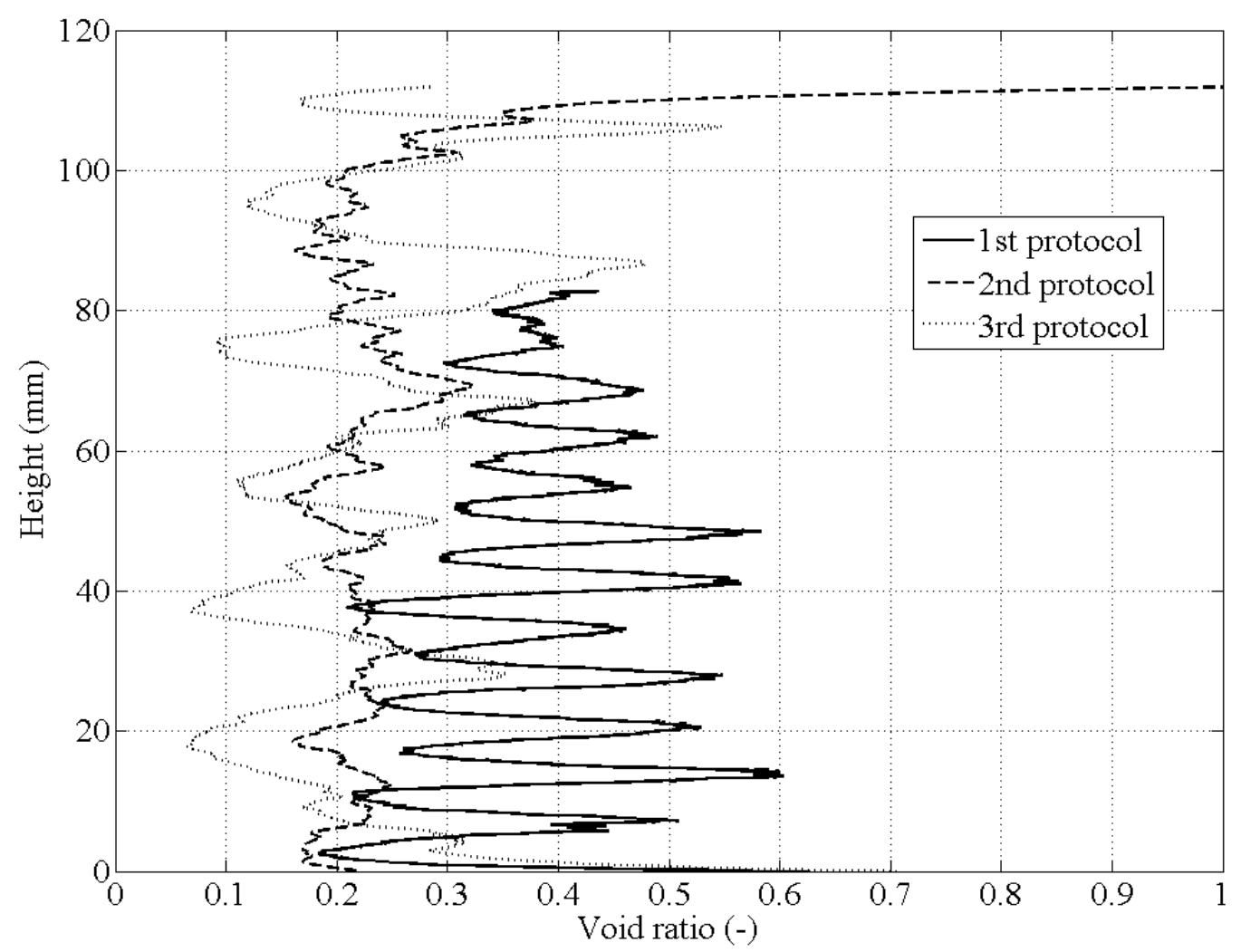

Figure 11. Evolution of the void ratio along height of a pellet/powder MX80 bentonite mixture (80/20) fabricated by three protocols. 

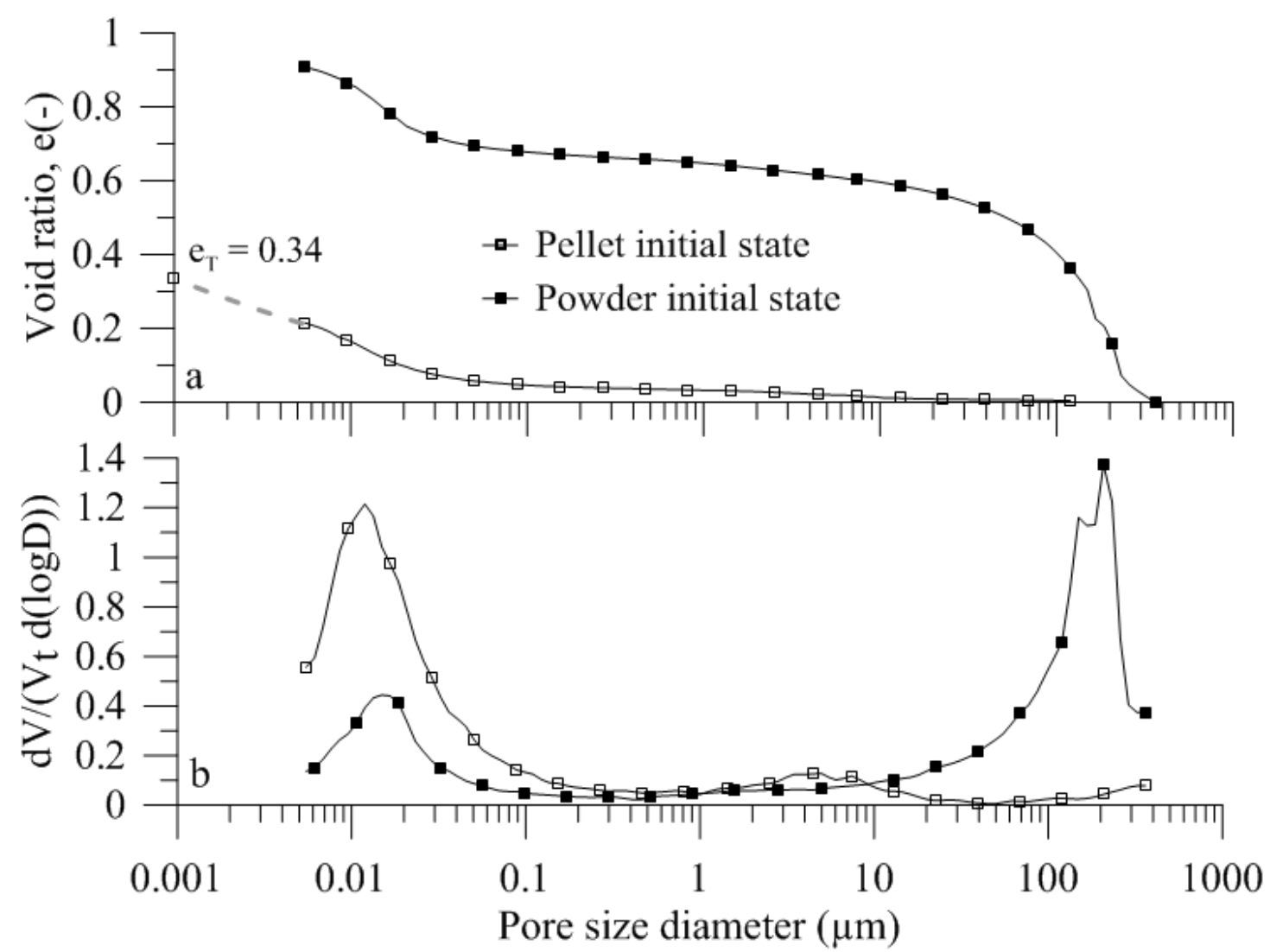

Pore size diameter $(\mu \mathrm{m})$

566

567

568

569

570

571

572

573

574

575

576

577

578

579

Figure 12. Cumulative porosity curve (a) and derivative curve (b) for a pellet and powder of bentonite at their initial state. 

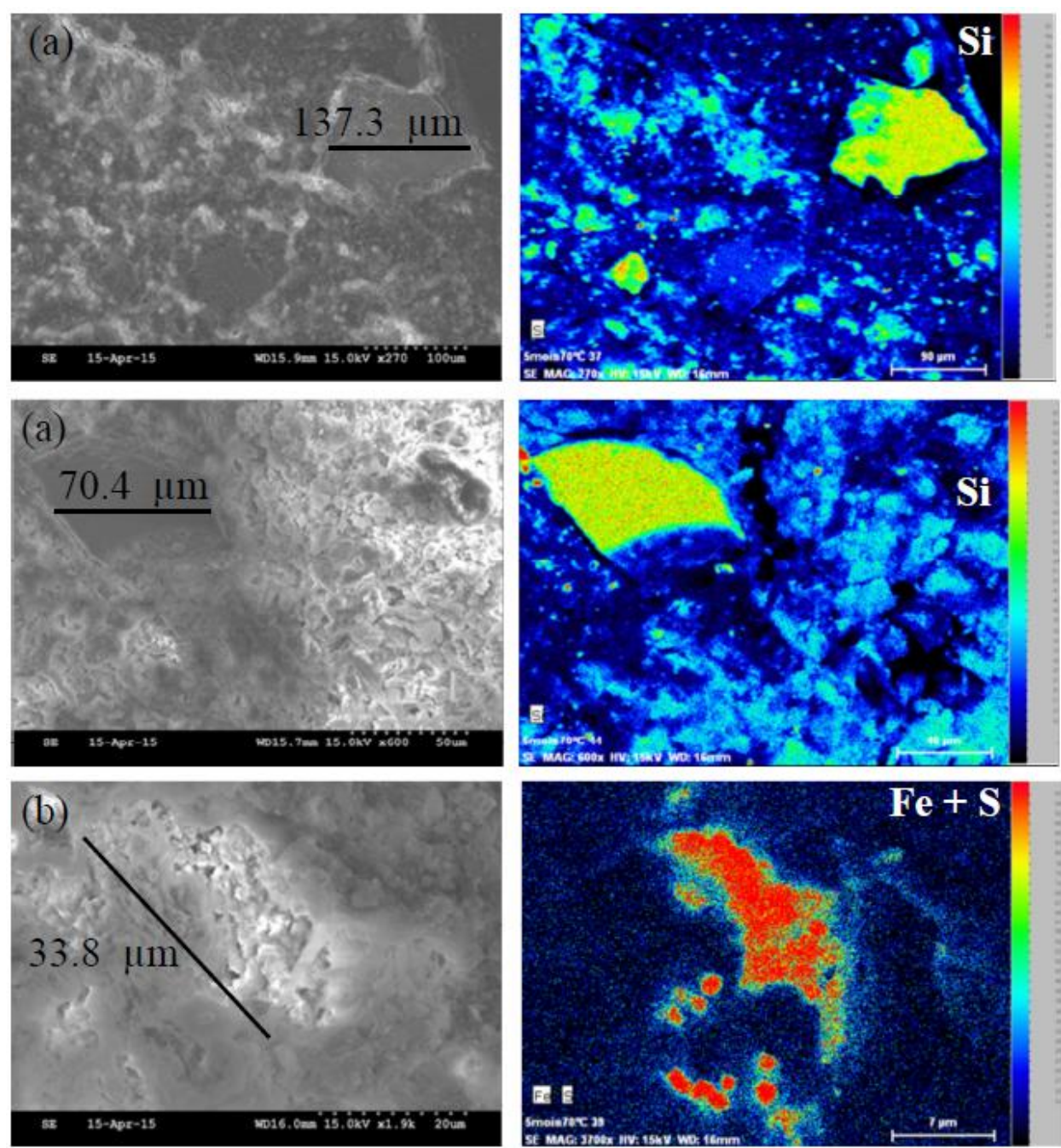

Figure 13. SEM pictures taken on a pellet of bentonite at its initial state (132.38 MPa of suction $)+$ EDS results. Mineral inclusions of quartz $(\mathrm{a}, \mathrm{b})$ and pyrite $(\mathrm{c})$. Dry unit mass $\rho_{d}=$ $2.12 \mathrm{Mg} / \mathrm{m}^{3}$ 

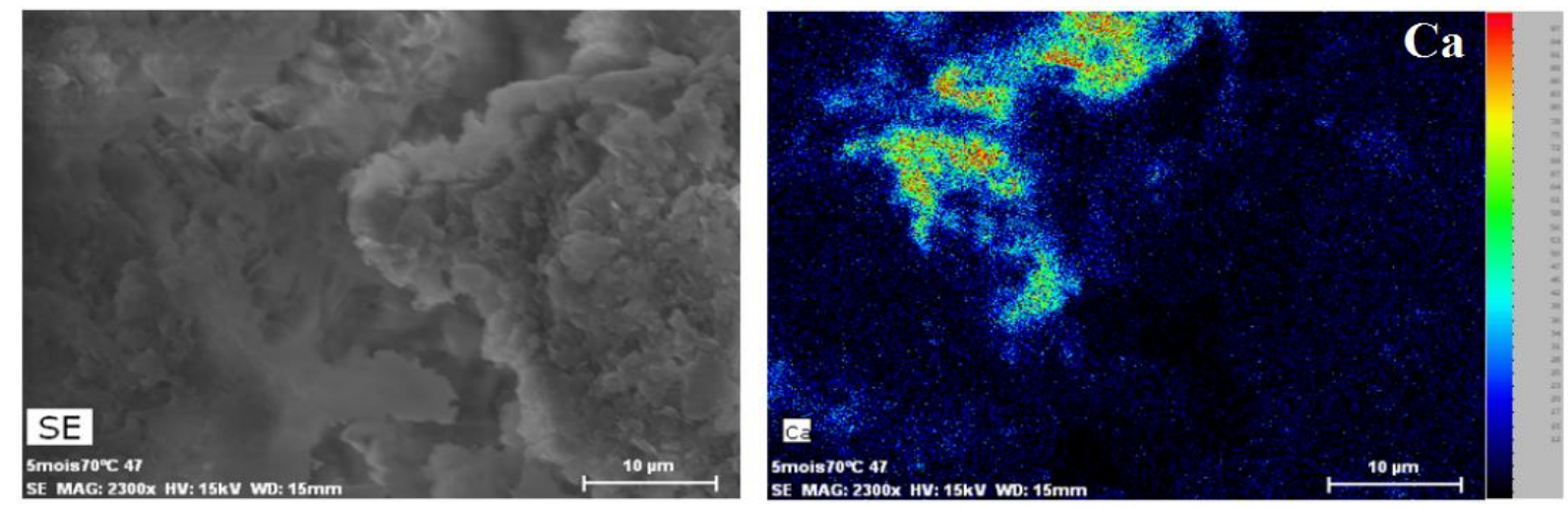

Figure 14. SEM picture taken on a pellet of bentonite at its initial state (132.38 MPa of suction) + EDS results. Mineral inclusion of calcite. Dry unit mass $\rho_{d}=2.12 \mathrm{Mg} / \mathrm{m}^{3}$ 